\title{
Effects of Root Extracts of Withania Coagulans on Withdrawal Syndrome in Albino Mice
}

\author{
Karami Mohammad*,1 and Gohari Ahmed Reza ${ }^{2}$
}

${ }^{I}$ Department of Toxicopharmacology, School of Pharmacy, Mazandaran University of Medical Sciences, Sari, 0098151,
Iran; ${ }^{2}$ Medical Plants Sciences Research Center, Tehran School of pharmacy, Medical Sciences University of Tehran,
Tehran, 009821, Iran

\begin{abstract}
It is known that repeated use of opioid drugs causes physical dependence and tolerance. Dependance can be measured by evocation of abstinence sign by abrupt drug withdrawal or administration of a narcotic antagonist or both. After induction of dependence by morphine, mice are divided in to seven groups using distilled water as the control group. The other six groups were injected by different concentrations of plant root extract. To assess morphine withdrawal, mice injected naloxone $(5 \mathrm{mg} / \mathrm{kg})$ i.p. on the day $4^{\text {th }}$ after three consecutive days of morphine injection, withdrawal syndrome was assessed by placing each mouse in a $30 \mathrm{~cm}$ high glass box and recording the incidence of escape jumps for 60 mins. Animal receiving acute treatment with morphine displayed dependence. The Albino mice treated with alcoholic, chloroform and ethyl acetate extracts of Withania coagulans roots could decrease incidence of escape jumps in number or decrease development of morphine dependence and other hand addiction following naloxone administration.
\end{abstract}

Keywords: Morphine, naloxone jumping, opioid, withania coagulans, withdrawal syndrome,

\section{INTRODUCTION}

It is known that repeated use of opioid drugs causes physical dependence and tolerance. Dependence can be measured by evocation of abstinence sign by abrupt drug withdrawal or administration of a narcotic antagonist or both [1]. Jumping is most suitable sign of measuring abstinence quantity as jumps are easily counted and jumping rate increases when dependence increases or dose of antagonist increased.

Withania coagulans (Stocks) Dunal (Solanaceae), known as Indian rennet or vegetable rennet, is a shrub commonly distributed in Iran, Afghanistan, Pakistan, and India [2]. The fruits have the property of coagulating milk, and has been used for preparing a vegetable rennet ferment for making cheese [3]. The fruit extract of W. coagulans can significantly lower the blood sugar, serum cholesterol, serum lipid peroxidation (LPO), and hepatic LPO levels [4]. Previous investigations on $\mathrm{W}$. coagulans revealed its beneficial effects to decrease dependence sign produced by morphine [1]. Administration of W. somnifera (L.) Dunal $(100 \mathrm{mg} / \mathrm{kg})$ for 9 days attenuated the development of tolerance to the analgesic effect of morphine $(10 \mathrm{mg} / \mathrm{kg})$. W. somnifera $(100 \mathrm{mg} / \mathrm{kg})$ also suppressed morphine-withdrawal jumps, a sign of the development of dependence to opiate as assessed by naloxone $(2 \mathrm{mg} / \mathrm{kg})$ precipitation withdrawal on day 10 of testing [5-6]. The present experiments were undertaken to study the protective effect of $\mathrm{W}$. coagulans root extract on the development of dependence to morphine in mice.

\footnotetext{
* Address correspondence to this author at the Department of Toxicopharmacology, School of Pharmacy, Mazandaran University of Medical Sciences, Sari, 0098151, Iran; Tel: +98 152 3543083-6; Fax: +98 152 3543082; E-mail: toxkarami@gmail.com
}

\section{MATERIALS AND METHODS}

\section{Plant Material}

Roots of Withania coagulans were collected from Mazandaran in November 2009 and dried in shade followed by grinding. The withania coagulans was identified by Dr. Gohari, Herbarium of Tehran University and voucher samples were preserved for reference at the herbarium in Department of Pharmacognosy, School of Pharmacy, Tehran, Iran (0506$15)$.

\section{Preparation and Fractionation}

Air-dried root powder was fractionated by solvent extraction at $48 \mathrm{~h}$ (3 times) by percolation with ethyl acetate, chloroform and finally methanol successively. The mixture was filtered and the filtrate was concentrated to dryness. For pharmacological studies the residue was prepared in phosphate buffer $(\mathrm{pH}=7.4)$ and Tween $80(4: 1)$.

\section{Animals}

Albino mice of either sex $(\mathrm{n}=10,25-30 \mathrm{~g})$ were used. Animals were housed under standard condition of temperature $\left(25 \pm 2{ }^{\circ} \mathrm{C}\right), 12 \mathrm{~h} / 12 \mathrm{~h}$ light dark cycles and fed with standard pelleted diet and water was given ad libitum. Animal handling was performed as per Good Laboratory Practice. A research proposal was prepared according to the guidelines of Committee for the Purpose of Control and Supervision of Experiments on Animals (CPCSEA).The Institutional Animal Ethical Committee (IAEC) of Mazandaran University of medical sciences approved the proposal.

\section{Morphine Dependence}

Morphine was injected intraperitoneal (i.p.) to mice at doses of 50,50 , and $75 \mathrm{mg} / \mathrm{kg}$ three times daily (10:00, 


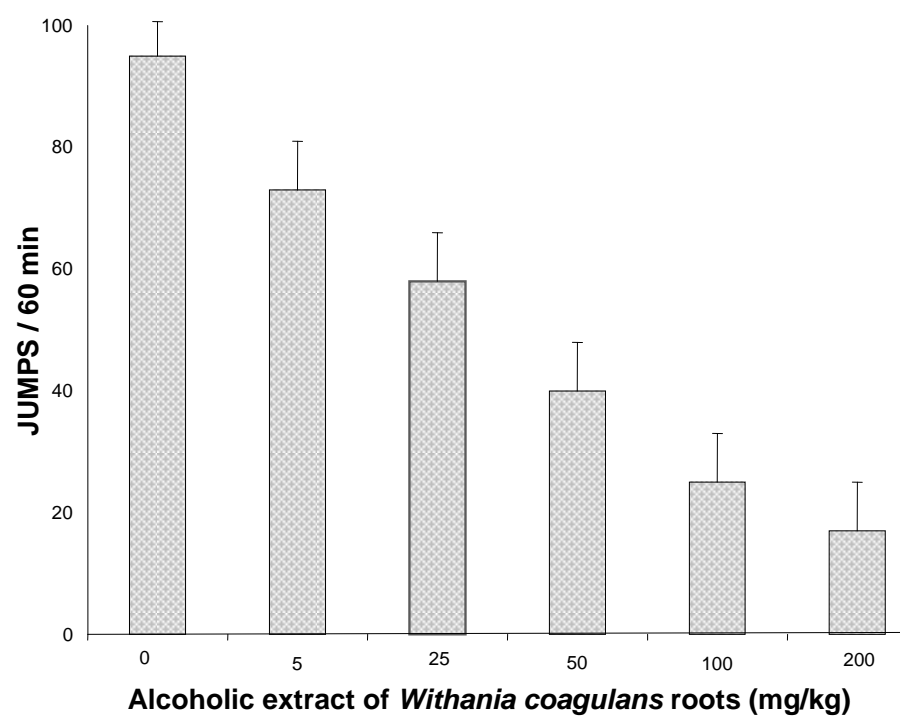

Fig. (1). Effects of alcoholic extract of Withania coagulans roots on morphine withdrawal jumps (Mean \pm SEM, $\mathrm{P}<0.01)$.

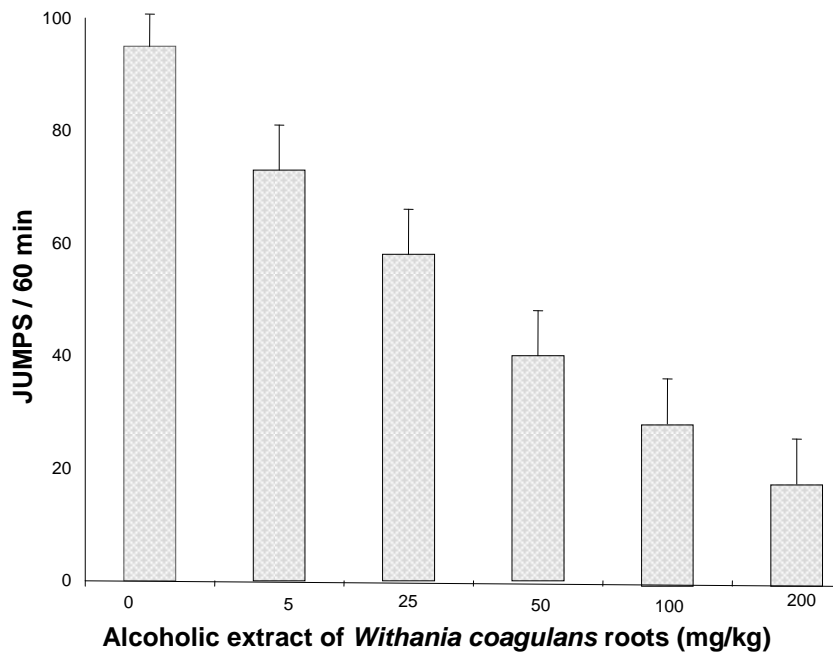

Fig. (2). Effects of chloroform extract of Withania coagulans roots on morphine withdrawal jumps (P < 0.01; error bars, S.E.M.).

13:00, and 16:00 h, respectively) for 3 days. On day 4 , a single dose of morphine $(50 \mathrm{mg} / \mathrm{kg}$ ), was injected $2 \mathrm{~h}$ before naloxone treatment.

\section{Morphine Withdrawal}

Withdrawal signs were elicited by the injection of naloxone $(5 \mathrm{mg} / \mathrm{kg}$, s.c.) 2 hafter the final administration of morphine. After the naloxone challenge, mice were immediately placed in a glass cylinder $(30 \times 20 \mathrm{~cm})$. The number of jumping episodes was counted for $60 \mathrm{~min}$ after naloxone injection.

\section{Drug and Fractions Treatment}

After induction of dependence by morphine, mice are divided in to seven groups.To the control group distilled water was injected $(10 \mathrm{~mL} / \mathrm{kg}$, i.p.) and to the other groups different concentrations of root extract were injected $(5,25,50$, 100 , and $200 \mathrm{mg} / \mathrm{kg}$, i.p.) $0.5 \mathrm{~h}$ after the final dose of morphine. Withdrawal syndrome was assessed by counting the number of jumping episodes for $60 \mathrm{~min}$ after naloxone injection $[1,6-8]$.

\section{Statistical Analysis}

Statistical analysis was performed using SPSS for Windows (ver.10, SPSSInc., Chicago, USA). Data were analyzed by one-way analysis of variance (ANOVA) followed by the multiple comparison test of Tukey-Kramer and presented as Mean \pm Standard error $(\mathrm{SEM})$. In all cases $\mathrm{P}<0.05$ was taken as statistically significant.

\section{RESULTS AND DISCUSSION}

Animal receiving acute treatment with morphine displayed dependence. The animal treated with different $W$. coagulans root extract concentration could decrease or increase incidence of escape jumps in number following naloxone administration. The result from this study have shown the high inhibition of morphine dependence in chloroform and alcoholic extracts of roots of $W$. coagulans can decrease development of morphine dependence Figs. (1, 2, 


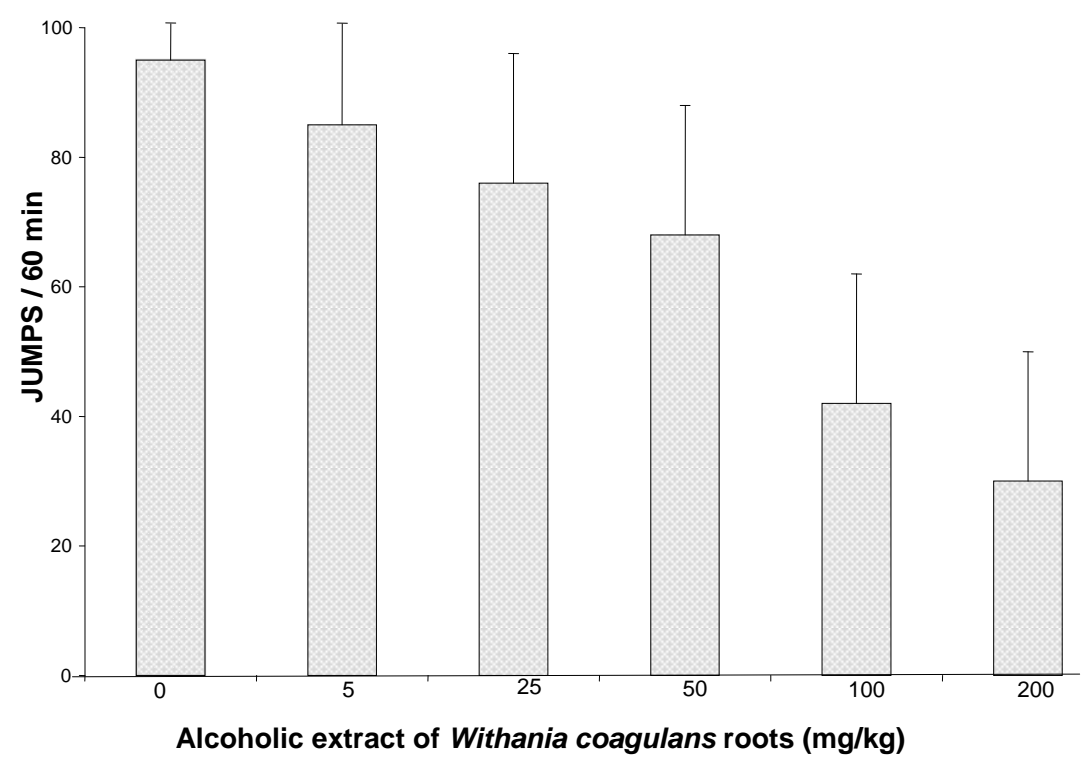

Fig. (3). Effects of ethyl acetate extract of Withania coagulans roots on morphine withdrawal jumps (mean \pm S.E.M, P<0.01).

and 3). Mechanism of plant action to W. coagulans to inhibit or decrease abstinence syndrome in dependent mice need to be further investigated.

Fruit and root of W. coagulans are used in treating burns and infectious wounds, arthritis, inflammation and rheumatism [9]. According to a study from India [10], administration of aqueous extract of fruits of W. coagulans signifycantly lowered the blood sugar, serum cholesterol, serum LPO, and hepatic LPO levels at the highest concentration of $1 \mathrm{~g} / \mathrm{kg}$; po in streptozotocin induced diabetic rats. In normal rats as well, the blood sugar levels were significantly decreased following treatment with the above drug. Withania coagulans also exhibited free radical scavenging activity in an in vitro system [9]. Two new withanolides, epoxywithanolide I and $17 \beta$-hydroxywithanolide $\mathrm{K}$ have been isolated from the whole plant of W. coagulans and their structures were elucidated by spectroscopic techniques and they have showed to be active against a number of potentially pathogenic fungi [10]. The identification of polyphenols as biologically active compounds has been previously reported $[1,11]$. Withania coagulans has shown protection against development of dependence by morphine [5, 12-13]. Recently we have shown the high inhibition of morphine dependence in chloroform, alcoholic and ethyl acetate extracts of roots of W. coagulans. Alcoholic extract of roots of $\mathrm{W}$. coagulans was safe and showed a high protective effect. The next portions, chloroform and ethyl acetate extract were moderate protective effect on the development of dependence to morphine in mice [14].

The alcoholic, chloroform, and ethyl acetate extracts of W. coagulans roots caused significant decrease in development of morphine dependence and other hand addiction following naloxone administration when compared to the control groups Fig. (1, 2, and 3). Protective effect was generally dose-dependent. The highest activity showed in alcoholic and chloroform extract of roots that at $200 \mathrm{mg} / \mathrm{kg}$ i.p. inhibited $97 \%$ and $95 \%$ incidence of escape jumps (for $60 \mathrm{~min}$ ) respectively. These activities were comparable after induction of dependence by morphine at $30 \mathrm{mg} / \mathrm{kg}$ i.p. and assess morphine withdrawal by injection of naloxone $(5 \mathrm{mg} / \mathrm{kg})$ i.p. as treatment protocol in mice.

\section{CONCLUSION}

The experiments showed that alcoholic, chloroform, and ethyl acetate extracts extracts of $\mathrm{W}$. coagulans roots can protect the morphine withdrawal syndrome in Albino mice. The results are valuable as a step towards the search for different mechanism of actions, which may be involved in the inhibitory effect of the extract on morphine dependency. However, it is difficult to speculate on the exact mechanism of action at this time.

\section{CONFLICT OF INTEREST}

The authors confirm that this article content has no conflicts of interest.

\section{ACKNOWLEDGEMENTS}

This work was supported by a grant from the research council of the Mazandaran University of Medical Sciences, Iran.

\section{ABBREVIATIONS}

CPCSEA $=$ Committee for the Purpose of Control and Supervision of Experiments on Animals

IAEC $=$ The Institutional Animal Ethical Committee

LPO $\quad=$ Lipid Peroxidation

\section{REFERENCES}

[1] Hhadjiakhondi, A.; Gohar, A. R . Inhibition of morphine dependence by Withania coagulans in mice. International Congress on Traditiona Medicine and Materia Medica, Tehran, Iran, 2000.

[2] Khodaei, M.; Jafari, M.; Noori, M. Remedial Use of Withanolides from Withania Coagolans (Stocks) Dunal. Adv. Life Sci., 2012, 2(1), 6-19.

[3] Atal, C.K; Sethi, P.D.A. Preliminary chemical examination of Withania coagulans. Indian J. Pharm., 1963, 25, 163-164. 
[4] Hemalatha, S.; Wahi, A.K.; Singh, P.N.; Chansouria, J.P.N. Hypoglycemic activity of Withania coagulans Dunal in streptozotocin induced diabetic rats. J. Ethnopharmacol., 2004, 93, 261-264.

[5] Kulkarni, K.; Ninan, I. Inhibition of morphine tolerance and dependence by in mice. J. Ethnopharmacol., 1997, 57, 213-217.

[6] Gomaa, A.; Hashem, T.; Mohamed, M. E.; Ashry, A. Matricaria chamomoilla extract inhibits both development of morphine dependence and expression of abstinence syndrome in rats. J. Pharmacol. Sci., 2003, 92(1), 50-55.

[7] Marshall, I.; Grahme-Smith, D.G. Evidence against a role of brain 5-hydroxyl tryptamine in development of physical dependence upon morphine in mice. J. Pharmacol. Exp. Ther., 1971, 179, 634641.

[8] Hosseinzadeh, H.; Lari, P. Effect of Salvia leriifolia extract on morphine dependence in mice. Phytother Res., 2000, 14, 384-387.
[9]

NewsRx/Drug

Week.

Available

at:

http:// www.newsrx.com/newsletters/Drug-week.html, [Accessed October $8,2004]$.

[10] Budhiraja, R. Anti-inflamatory activity of withanolide F. Planta Med., 1984, 50, 134-136.

[11] Harborne, J.B. Phytochemical methods aguide to modern technique of plant analysis. $3^{\text {rd }}$ ed. London: Chapman \& Hall, 1998.

[12] Choudhary, M.I.; Shahwar, D.E.; Parveen, Z.; Jabbar, A.; Atta-urRahman, A.I. Anti fungal steroidal lactones from Withania coagulans. Phytochemistry, 1955, 40(4), 1243-1246.

[13] Zhu, M.; Phillipson, J.D.; Greengrass, P.M.; Bowery, N.E.; Cai, Y. Plant polyphenols: biologicaly active compounds or non-selective binders to protein? Phytochemistry, 1997, 44(3), 441-447.

[14] Ramassamy, C.; Clostre, F.; Christen, Y.; Costentin, J. Privention by a Ginkgo biloba extract of the dopaminergic neurotoxicity of MPTP. J. Pharm. Pharmacol., 1990, 42, 758-789.

Received: April 24, 2012

Revised: July 18, 2012

Accepted: July 19, 2012

() Mohammad and Reza; Licensee Bentham Open.

This is an open access article licensed under the terms of the Creative Commons Attribution Non-Commercial License (http://creativecommons.org/ licenses/ by-nc/3.0/) which permits unrestricted, non-commercial use, distribution and reproduction in any medium, provided the work is properly cited. 